\title{
One-Step and In-situ Decoration of High-Quality Graphene with Transition Metal Oxide Nanoparticles
}

\author{
Wen Qian, ${ }^{1}$ Steven Cottingham, ${ }^{1}$ Zhiqiang Chen, ${ }^{2}$ Aaron Besser, ${ }^{1}$ Jun Jiao ${ }^{1 *}$ \\ ${ }^{1}$ Department of Physics, Portland State University (PSU), Portland, OR 97201 \\ ${ }^{2}$ Center for Electron Microscopy and Nanofabrication, PSU, Portland, OR 97201 \\ * Prof. Jun Jiao, Corresponding Author, jiaoj@pdx.edu
}

Graphene, as a new member of carbon allotropes family, has exhibited potential applications due to its unique electronic and mechanical properties [1-2]. In view of its highly specific surface area [1] and super electrical conductivity [2], graphene is being considered as an ideal template for loading transition metal oxides, which could manufacture various graphene-based composites for energyrelated electrochemical devices [3]. In this abstract, monodispersed magnetic iron oxide nanoparticles (NPs) have been successfully deposited onto the surface of exfoliated graphene by a simple solvothermal process at a temperature of $180{ }^{\circ} \mathrm{C}$, using iron (II) acetylacetonate and expanded graphite as precursor, and using anhydrous ethanol as the solvent. The transmission electron microscopy (TEM) micrographs show the graphene/ $\mathrm{Fe}_{3} \mathrm{O}_{4}$ composites prepared by a solvothermal process at $180{ }^{\circ} \mathrm{C}$ for $4 \mathrm{~h}, 8 \mathrm{~h}$, and $16 \mathrm{~h}$ respectively, in Fig. 1a-c. The results indicate that the particle size and coating density can be tailored by varying reaction times. The high resolution EM image (HREM) confirmed that the attached $\mathrm{Fe}_{3} \mathrm{O}_{4}$ NPs are well crystallized, the lattice spacing was about $0.24 \mathrm{~nm}, 0.29 \mathrm{~nm}$ (Fig. 1d) and $0.29 \mathrm{~nm}$ (Fig. 1e) which are correspondent with the (-2-22), (2-20) and (220) plane in a cubic spinel $\mathrm{Fe}_{3} \mathrm{O}_{4}$. The correspondent selected area electron diffraction pattern (SAED) from the graphene $/ \mathrm{Fe}_{3} \mathrm{O}_{4}$ composites shows the diffraction rings which are coincident with the graphene (002) lattice plane and magnetite $\mathrm{Fe}_{3} \mathrm{O}_{4}$ phase, (220), (311), (400), (511), (440), from inner to outside respectively, as shown in Fig. 1e (insert). It further confirms the formation of $\mathrm{Fe}_{3} \mathrm{O}_{4}$ on the graphene. Fig. 1f shows the typical Energy-dispersive X-ray spectroscopy (EDX) pattern of deposited $\mathrm{Fe}_{3} \mathrm{O}_{4} \mathrm{NPs}$.

Our results demonstrate that this simple and environmental-friendly chemical process, in general, can be used to combine graphene and other transition metal oxide NPs, such as $\mathrm{Mn}_{3} \mathrm{O}_{4}$ (Fig. 2) and $\mathrm{CoO}$ by changing manganese (II) acetylacetonate or cobalt (II) acetylacetonate as precursor. Fig. 2a$\mathrm{b}$ shows the micrographs taken from the graphene $/ \mathrm{Mn}_{3} \mathrm{O}_{4}$ composites prepared by a solvothermal process at $200{ }^{\circ} \mathrm{C}$ for $8 \mathrm{~h}$ and $16 \mathrm{~h}$ respectively. The results indicate that the particle size increase from $10 \mathrm{~nm}$ to $25 \mathrm{~nm}$ when reaction times extends. HREM images also confirmed that the deposited $\mathrm{Mn}_{3} \mathrm{O}_{4}$ NPs are well crystallized, the lattice spacing was about $0.25 \mathrm{~nm}, 0.28 \mathrm{~nm}$ (Fig. 2c) and 0.49 $\mathrm{nm}$ (Fig. 2d) which are correspondent with the (1-10) (200) and (112) plane in spinel $\mathrm{Mn}_{3} \mathrm{O}_{4}$. The inserted SAED image shows the diffraction rings, are from the graphitic carbon (002) plane and Hausmannite $\mathrm{Mn}_{3} \mathrm{O}_{4}$ phase, (112), (103), (211), (220), (105), (321) planes.

To investigate the potential application of graphene $/ \mathrm{Mn}_{3} \mathrm{O}_{4}$ composite as the electrode material for a supercapacitor, as well as graphene $/ \mathrm{Fe}_{3} \mathrm{O}_{4}$ and graphene/CoO composites in Lithium ion batteries, further work will be explored for measurement the cyclic voltammetry curves, galvanostatic charge/discharge curves and cycle stability.

References

[1] S. Stankovich et al., Nature, 442 (2006) 282. 
[2] X. Du et al., Nature Nanotechnology 3 (2008) 491.

[3] C. Xu et al., Journal of Physical Chemistry C 112 (2008) 19841.

[4] This research was supported in part by the funds from the NSF and ONAMI.
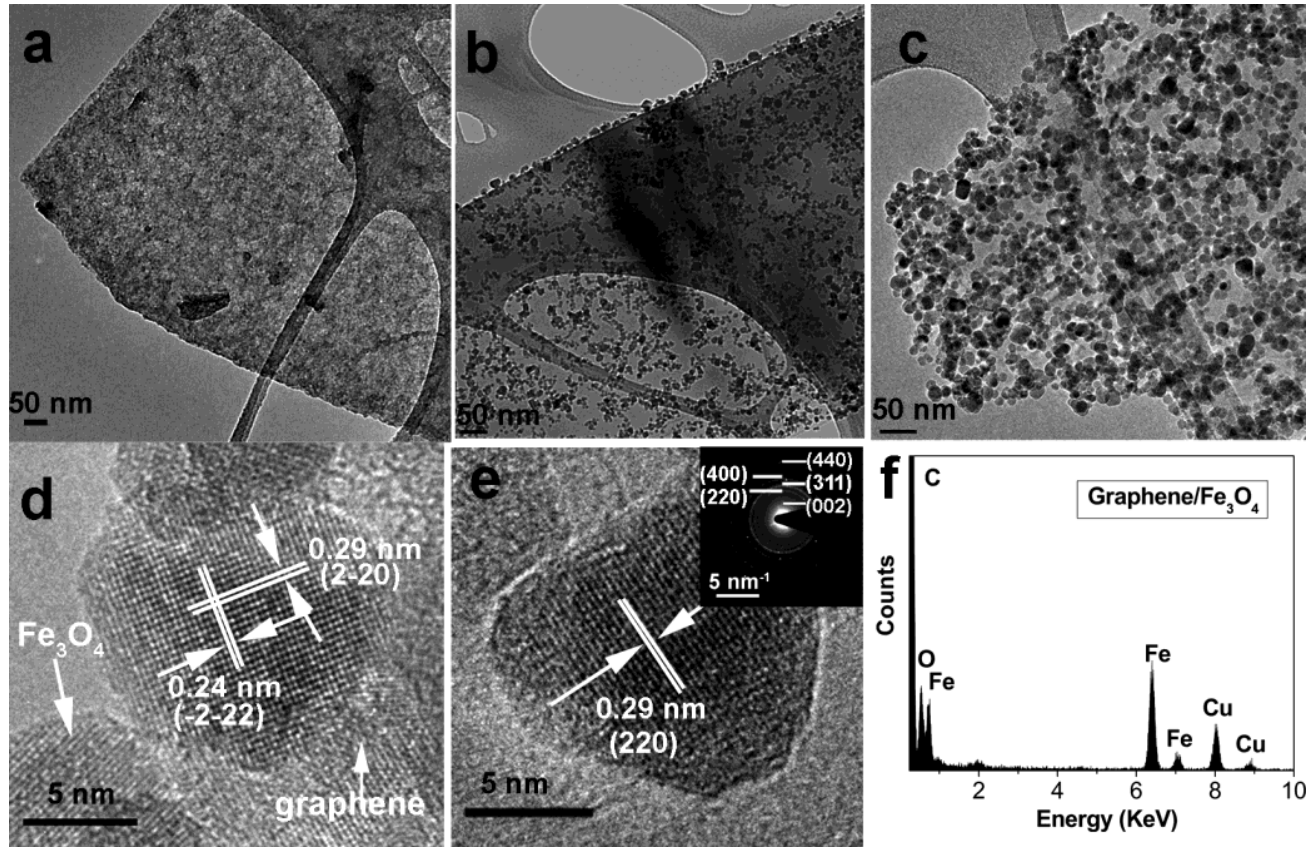

FIG. 1. TEM analysis of graphene/ $\mathrm{Fe}_{3} \mathrm{O}_{4}$ composite prepared by a solvothermal process at $180 \mathfrak{C}$. (a)-(c) the reaction time for $4 \mathrm{~h}, 8 \mathrm{~h}, 16 \mathrm{~h}$ respectively; (d)-(e) HREM micrographs of deposited $\mathrm{Fe}_{3} \mathrm{O}_{4}$ NPs and the corresponding SAED pattern (insert); (f) EDX pattern of the deposited $\mathrm{Fe}_{3} \mathrm{O}_{4}$ NPs.
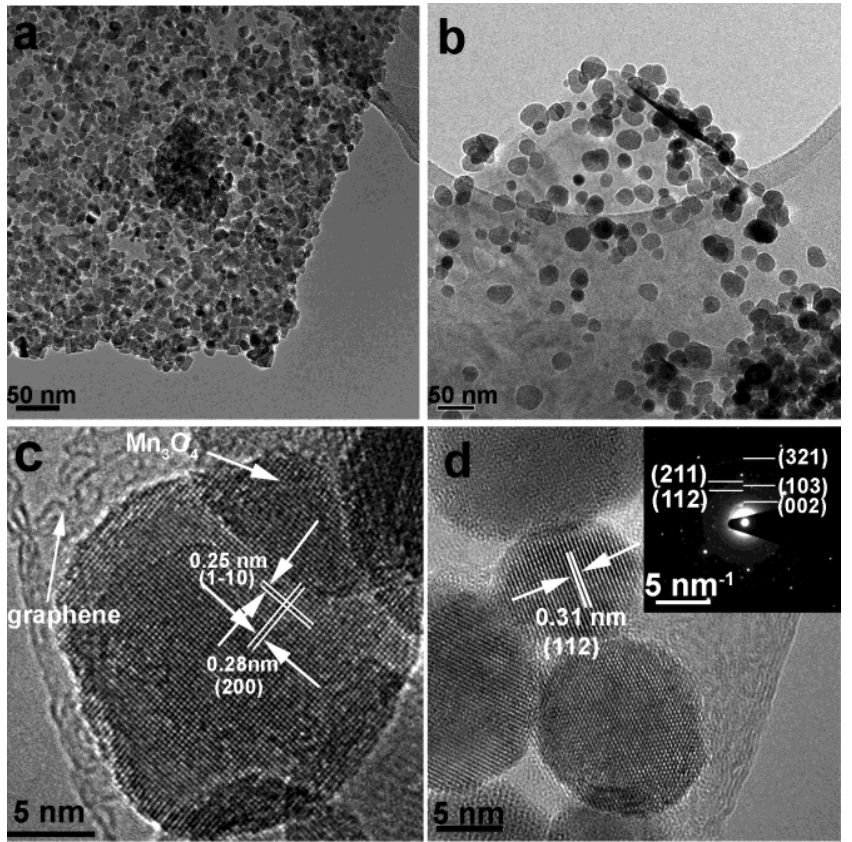

FIG. 2. TEM analysis of graphene/ $\mathrm{Mn}_{3} \mathrm{O}_{4}$ composite prepared by a solvothermal process at $200 \mathfrak{C}$. (a)-(b) the reaction time for $8 \mathrm{~h}$ and $16 \mathrm{~h}$ respectively; (d)-(e) HREM micrographs of deposited $\mathrm{Mn}_{3} \mathrm{O}_{4}$ NPs and the corresponding SAED pattern (insert). 